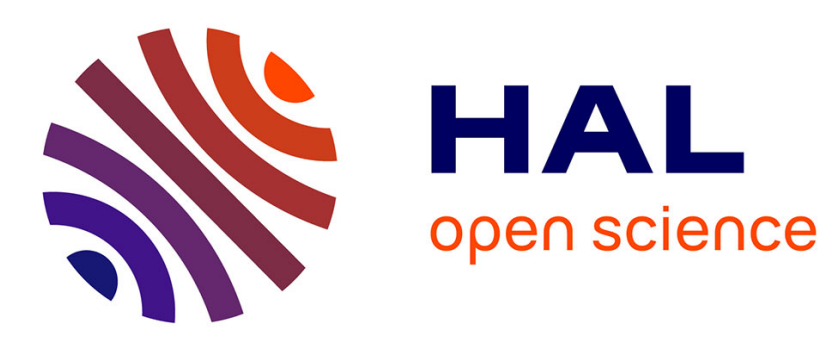

\title{
From Physiological Measures to an Automatic Recognition System of Stress
}

\author{
Nicolas Martin, Jean-Marc Diverrez
}

\section{To cite this version:}

Nicolas Martin, Jean-Marc Diverrez. From Physiological Measures to an Automatic Recognition System of Stress. HCI International 2016, Jul 2016, Toronto, Canada. pp.139 - 176, 10.1007/978-3319-40542-1_27. hal-01525673

\section{HAL Id: hal-01525673 https://hal.science/hal-01525673}

Submitted on 29 May 2017

HAL is a multi-disciplinary open access archive for the deposit and dissemination of scientific research documents, whether they are published or not. The documents may come from teaching and research institutions in France or abroad, or from public or private research centers.
L'archive ouverte pluridisciplinaire HAL, est destinée au dépôt et à la diffusion de documents scientifiques de niveau recherche, publiés ou non, émanant des établissements d'enseignement et de recherche français ou étrangers, des laboratoires publics ou privés. 


\title{
From physiological measures to an automatic recognition system of stress
}

\author{
Nicolas Martin ${ }^{1}$, Jean-Marc Diverrez ${ }^{1}$ \\ ${ }^{1}$ Uses \& Acceptability Lab, $\mathrm{b}<>$ com, France \\ \{nicolas.martin, jean-marc.diverrez $@ @ b-c o m . c o m$
}

\begin{abstract}
Evaluation of stress is mainly based on standardized scales [1]. However, fill out questionnaires can be incompatible with several situations (e.g. during chirurgical intervention) [2] and offers only subjective and punctual data. Physiological measures, which provided real-time and objective data [3], can be used to cope with these constrains. To be effective, physiological data need to be related to human feeling. One solution is to build an automatic recognition system of stress based on supervised machine learning. Thereby, to acquire physiological data, we built stressful situation in laboratory. From physiological data (respiratory, cardiac and electrodermal measurement) of 24 participants, we built a model that recognizes stress with an accuracy of $70 \%$.
\end{abstract}

Keywords: Stress, Physiological Measurement, Automatic Recognition, Machine Learning

\section{Introduction}

Stress is a serious concern facing our world today. We need to develop a better and objective understanding of this concept, through the use of non-intrusive means for stress recognition, and without troubling natural human behavior. The human body undergoes several physiological changes when exposed to acute stressors. More precisely, electrodermal activities, heart rate activities, and respiration activities data are commonly used to measure short-term emotional and cognitive stress. The goal of the current study is to build an automatic recognition system of stress from physiological measures based on supervised machine learning. For this, annotated data are required [8]. For the same reason that scales are not always adapted to evaluate stress, construct an annotated database in real situation can be very complex. One solution is to build stressful situations in laboratory and collect data. We selected this solution to induce stress and to construct our annotated database. More precisely, we proposed two types of situations (stressful or not stressful) to participants and measured physiological indexes during the experiment. 


\subsection{Stress Measurements}

To recognize stress, it is first necessary to be able to measure it. Currently, evaluation of stress is mainly based on two methods: standardized scales [1] and physiological data [e.g. 4].

\section{Subjective evaluations.}

Standardized scales are the most commonly used method to evaluate stress. Scales have several advantages: they are ease to use, free and provide rapid results. However, it can be complex under several circumstances. Thereby, asking individuals to fill scales can be incompatible with several situations (e.g. during chirurgical intervention) [2]. Moreover, per definition, data from scales are subjective and punctually acquired. To cope with these two constrains, physiological measures have been developed.

\section{Physiological measurements.}

Physiological measurements, unlike subjective measurements, can provide real-time and objective data [3]. Thereby, many studies have explored the link between physiological responses and stress. Such responses may be modifications and variability of heart rate, modifications of breathing rate, blood pressure and galvanic skin activity [5]. For example, Shi et al. [4] showed a strong correlation between stress levels and electrodermal activity (EDA). Healey et al. [6] showed a correlation between breathing rate and stress levels. Lastly, Sierra De Santos et al. [7] showed the relevance of measuring stress by measurements of electrodermal and heart activity.

\section{$2 \quad$ Method}

\subsection{Material}

In previous research, several paradigms have been used to induce stress: ranging from simple tracking tasks [9] to more complex methods like the Montreal Imaging Stress Task [10]. In our experiment, induction of stress is based on the procedure proposed by Campbell [11] to investigate the effect of time pressure on simple mathematical operations. Thereby, we created stressful situations where individuals had to carry out additions under time pressure. Two conditions were created:

- Condition 1 - Not stressful situation: participants had to answer following a beep sound occurring $2650 \mathrm{~ms}$ after the calculation was presented.

- Condition 2 - Stressful situation: participants had to answer before a beep sound and the beep occurred $900 \mathrm{~ms}$ after the calculation was presented.

For each experimental condition, there were 36 trials ( 2 conditions: 72 trials per participant). Each trial consisted of a simple mathematical sum, such as " $2+7$ " or " $5+8$ ". 


\subsection{Physiological measurement}

The following physiological indexes were measured: cardiac, respiratory and electrodermal responses. Biopac Bionomadix MP150 was used to measure physiological responses. To build our automatic recognition system of stress, we used the following indexes on physiological data: electrodermal activities (EDA), heart rate activities (ECG RR / ECG R Wave) and respiration activities (Respiratory Rate). For each index, we computed the mean and standard deviation by trial.

\subsection{Subjective measurement}

After each condition, participants filled out two standardized scales to ensure of the effect of induced stress on subjective feeling. The first questionnaire is the Short Stress State Questionnaire (SSSQ) [12] that evaluates 3 aspects of the feeling of stress (Engagement, Distress and Worry). The second questionnaire is the Raw-TLX (RTLX) [13], a simplified version of the NASA Task Load Index . The RTLX assesses the perceived workload of a task as a simple sum of 6 dimensions (mental demand, physical demand, temporal demand, performance, effort, and frustration). The choice of these 2 questionnaires allows us to assess different aspects of the feeling of stress in our participants.

\subsection{Participants}

24 participants took part in the study and received in exchange a coupon for $€ 15$. All participants signed up with informed consent before beginning the experimental procedure and were informed about the goals of the study, procedures, cautions and ethical issues for the participation in the study.

\subsection{Procedure}

The following procedure was used during the experiment: before starting calculation, a baseline for physiological measurement is recorded. After, participants start calculation and all pass the 2 conditions (within-subject design). Between each condition, a break is observed to reduce stress level. To avoid order effect, the presentation of condition is counterbalanced and the presentation of the calculations is randomized.

\section{$3 \quad$ Results}

\subsection{Induction of stress}

To ensure that induction of stress is perceived by participants, we compare the subjective evaluation between the two conditions. Comparisons of models showed signifi- 
cant differences (see Table 1) for all dimensions of RTLX. For SSSQ, only distress is evaluated as significantly different between conditions.

Table 1. Descriptive statistics (Mean and Standard Deviation) for subjective measurement

\begin{tabular}{|c|c|c|c|c|c|c|}
\hline \multirow{3}{*}{ Scale } & \multirow{2}{*}{ Variable } & \multicolumn{2}{|c|}{ Condition 1 } & \multicolumn{2}{c|}{ Condition 2 } & \multirow{2}{*}{ Chi-square } \\
\cline { 3 - 6 } & & Mean & S.D. & Mean & S.D. & \\
\hline \multirow{5}{*}{ RTLX } & Mental demand & 16.46 & 19.86 & 57.29 & 36.77 & $\chi^{2}(1)=24.22 * * *$ \\
\cline { 2 - 6 } & Physical demand & 13.54 & 17.16 & 38.54 & 32.01 & $\chi^{2}(1)=14.73 * * *$ \\
\cline { 2 - 6 } & Temporal demand & 22.50 & 26.91 & 78.12 & 19.10 & $\chi^{2}(1)=43.82 * * *$ \\
\cline { 2 - 6 } & Effort & 18.75 & 23.69 & 68.96 & 24.14 & $\chi^{2}(1)=43.80 * * *$ \\
\cline { 2 - 6 } & Performance & 21.25 & 19.80 & 66.46 & 23.01 & $\chi^{2}(1)=37.31 * * *$ \\
\cline { 2 - 6 } & Frustration & 19.38 & 15.90 & 60.42 & 22.89 & $\chi^{2}(1)=42.52 * * *$ \\
\hline \multirow{3}{*}{ SSSQ } & Engagement & 30.12 & 5.79 & 29.38 & 4.75 & $\chi^{2}(1)=.85 \mathrm{NS}$ \\
\cline { 2 - 6 } & Worry & 13.04 & 4.64 & 13.79 & 5.35 & $\chi^{2}(1)=.60 \mathrm{NS}$ \\
\cline { 2 - 7 } & Distress & 10.00 & 1.67 & 16.29 & 6.48 & $\chi^{2}(1)=18.58 * * *$ \\
\hline
\end{tabular}

Signifiant codes: ***: $p<.001 ;$ NS : Non-Signifiant

\subsection{Machine learning}

Several methods of machine learning have been tested on physiological indexes: all these learnings have been conceived to be person-independent. To train the model and test the performance, the dataset was subset into a training dataset $(75 \%)$ and testing dataset $(25 \%)$. During the training, cross-validation was used and several algorithms have been tested. The Table 2 presented the comparison of this training. From these results, random forest was selected (accuracy $\approx 73.01 \%$ ). Finally, we tested the accuracy of the selected model on testing dataset with an accuracy of $70 \%$.

Table 2. Benchmark of machine learning algorithms

\begin{tabular}{|l|l|}
\hline Method & Accuracy for cross-validation \\
\hline Random Forest & $73.01 \%($ S.D. $=.05)$ \\
\hline Naïve Bayes & $69.38 \%($ S.D. $=.05)$ \\
\hline Neural Network & $68.05 \%($ S.D. $=.06)$ \\
\hline kNN & $63.24 \%($ S.D. $=.05)$ \\
\hline Support Vector Machine & $63.02 \%($ S.D. $=.05)$ \\
\hline
\end{tabular}

\section{Discussion and Conclusion}

Results indicated that machine learning algorithms offer a good framework to recognize stressful situation from physiological sensors. However, the sample is relatively small. Thus, to ensure of the reliability of our model, we need to conduct new studies on more participants. Moreover, in this study, the generation of stressful situation is 
only based on time pressure. It can be interesting to induce stress by imposing cognitive tasks on the individuals with the aim of exploring eventual specific physiological patterns.

In the future, this type of recognition system could be used to evaluate stress in real situation. Moreover, we planned to use this system to develop augmented Humancomputer interaction (AHCI). For example, we can imagine a medical interface which is automatically adapted to the user's stress level.

Acknowledgements. We thank all those who participated in any way in this research. This work was carried out within the Institute of Technological Research $b<>$ com and it received support from the French government under the program Future Investments bearing reference ANR-07-A0-AIRT.

\section{$5 \quad$ References}

1. Nübling, M., Stößel, U., Hasselhorn, H.-M., Michaelis, M., Hofmann, F.: Measuring psychological stress and strain at work - Evaluation of the COPSOQ Questionnaire in Germany. GMS Psycho-Soc. Med. 3, (2006).

2. Ryu, K., Myung, R.: Evaluation of mental workload with a combined measure based on physiological indices during a dual task of tracking and mental arithmetic. Int. J. Ind. Ergon. 35, 991-1009 (2005).

3. Rieder, R., Kristensen, C.H., Pinho, M.S.: Identifying Relationships between Physiological Measures and Evaluation Metrics for 3D Interaction Techniques. In: Campos, P., Graham, N., Jorge, J., Nunes, N., Palanque, P., and Winckler, M. (eds.) Human-Computer Interaction - INTERACT 2011. pp. 662-679. Springer Berlin Heidelberg (2011).

4. Shi, Y., Ruiz, N., Taib, R., Choi, E., Chen, F.: Galvanic Skin Response (GSR) As an Index of Cognitive Load. In: CHI '07 Extended Abstracts on Human Factors in Computing Systems. pp. 2651-2656. ACM, New York, NY, USA (2007).

5. Pickering, T.G., Devereux, R.B., James, G.D., Gerin, W., Landsbergis, P., Schnall, P.L., Schwartz, J.E.: Environmental influences on blood pressure and the role of job strain. J. Hypertens. Suppl. Off. J. Int. Soc. Hypertens. 14, S179-185 (1996).

6. Healey, J.A., Picard, R.W.: Detecting stress during real-world driving tasks using physiological sensors. IEEE Trans. Intell. Transp. Syst. 6, 156-166 (2005).

7. de Santos Sierra, A., Avila, C.S., Bailador del Pozo, G., Guerra Casanova, J.: Stress detection by means of stress physiological template. In: 2011 Third World Congress on Nature and Biologically Inspired Computing (NaBIC). pp. 131-136 (2011).

8. Kotsiantis, S.B.: Supervised Machine Learning: A Review of Classification Techniques. In: Proceedings of the 2007 Conference on Emerging Artificial Intelligence Applications in Computer Engineering: Real Word AI Systems with Applications in eHealth, HCI, Information Retrieval and Pervasive Technologies. pp. 324. IOS Press, Amsterdam, The Netherlands, The Netherlands (2007). 
9. Rubio, S., Diaz, E., Martin, J., Puente, J.M.: Evaluation of Subjective Mental Workload: A Comparison of SWAT, NASA-TLX, and Workload Profile Methods. Appl. Psychol. 53, 61-86 (2004).

10.Dedovic, K., Renwick, R., Mahani, N.K., Engert, V., Lupien, S.J., Pruessner, J.C.: The Montreal Imaging Stress Task: Using functional imaging to investigate the effects of perceiving and processing psychosocial stress in the human brain. In: Journal of Psychiatry and Neuroscience. pp. 319-325 (2005).

11. Campbell, J.I.D., Austin, S.: Effects of response time deadlines on adults' strategy choices for simple addition. Mem. Cognit. 30, 988-994 (2002).

12.Helton, W.S., Naswall, K.: Short stress state questionnaire: Factor structure and state change assessment. Eur. J. Psychol. Assess. 31, 20-30 (2015).

13. Hart, S.G., Staveland, L.E.: Development of NASA-TLX (Task Load Index): Results of Empirical and Theoretical Research. In: Hancock, P.A. and Meshkati, N. (eds.) Human Mental Workload. pp. 139-183. North-Holland (1988). 